\title{
Prevalence and associated factors of Tardive dyskinesia among psychiatric patients on first- generation antipsychotics at Jimma University specialized hospital, psychiatric clinic, Ethiopia: Institution based a cross-sectional study
}

Tilahun Abdeta ( $\nabla$ tilahunabdeta@gmail.com )

Haramaya University https://orcid.org/0000-0003-0971-9778

\section{Daniel Tolessa}

Adama hospital medical college, Adama, Ethiopia

Wondale Tsega

Adama hospital medical college, Adama, Ethiopia

Research article

Keywords: prevalence, associated factors, TD, first-generation antipsychotics, JUSH, Ethiopia

Posted Date: September 17th, 2019

DOI: https://doi.org/10.21203/rs.2.14536/v1

License: (c) (1) This work is licensed under a Creative Commons Attribution 4.0 International License.

Read Full License

Version of Record: A version of this preprint was published at Journal of Psychiatry and Psychiatric Disorders on January 1st, 2019. See the published version at https://doi.org/10.26502/jppd.2572$519 \times 0072$. 


\section{Abstract}

Background Tardive Dyskinesia is described as a movement disorder that can be caused by the prolonged use of antipsychotics. It is a permanent condition that affects quality of life. However, studies on TD among psychiatric patients in Ethiopia are limited. The objective of this study was to determine the prevalence and associated factors of Tardive dyskinesia among psychiatric patients on first-generation antipsychotics at Jimma University specialized hospital (JUSH) psychiatric clinic, Jimma, South west Ethiopia.Method Hospital based cross-sectional study was conducted using Abnormal Involuntary Movement Scale (AIMS) and Schooler and Kane research criteria to identify cases of first-generation antipsychotic-induced TD among 151 psychiatric outpatients on first-generation antipsychotics at Jimma University Specialized Hospital psychiatric clinic. Simple random sampling method was employed to select subjects from a total of 912 patients on follow-up and logistic regression analysis was employed to identify associated factorsResult In our study the prevalence of first-generation antipsychotic induced TD was $14.6 \%$ (95\% Cl: $10.76 \%, 18.4 \%)$. In the final model multivariate logistic regression analysis revealed that age (AOR 4.5, 95\% Cl: 9.7, 20.4), current smoking cigarettes (AOR 1.4, 95\% Cl: 2.6, 7.8) and chlorpromazine equivalent dose (AOR 6.5, 95\% Cl: 2.6, 26.8) had statistically significant association with first-generation antipsychotic induced TD.Conclusions Considerable number of psychiatric patients were suffered from first-generation antipsychotic induced TD. Age and current smoking cigarettes and chlorpromazine equivalent dose had significant association with first-generation antipsychotic induced TD. Therefore, stakeholders should consider and appropriately address these statistically identified associated factors in order to reduce antipsychotic induced TD.

\section{Background}

First-generation antipsychotics-induced movement disorders constitute a worldwide problem in the treatment of schizophrenia and related psychotic disorders because of the limited affordability of relatively safe second-generation antipsychotics [1]. Tardive dyskinesia (TD) is one of a group of side effects called antipsychotics induced movement disorders. TD is perhaps the most severe of these side effects and it is one of the most disturbing potential side effects [2]. Tardive Dyskinesia is a movement disorder that occurs over months, years and even decades after started antipsychotic medications [2]. The annualized TD incidence across first-generation antipsychotics arms was 6.5\% (95\% Cl: 5.3-7.8\%) vs. 2.6\% (95\% Cl: 2.0-3.1\%) across second-generation antipsychotics arms. TD risk and annualized rates were lower with second generation antipsychotics compared to first-generation antipsychotics $(R R=0.47$, 95\% Cl: 0.39-0.57, $p<0.0001, k=28 ; R a R=0.35,95 \%$ Cl: 0.28-0.45, $p<0.0001$, number-needed-to-treat, NNT=20) [3-5]. First-generation antipsychotic drugs are efficacious in the treatment of acute psychosis, chronic psychotic conditions and other psychiatric disorders [6]. Drugs in this class have comparable efficacy in the treatment of psychosis and include high potent drugs (haloperidol, thiothixene, fluphenazine, Trifluoperazine, perphenazine, loxapine, droperidol \& pimozide) and low potent drugs (chlorpromazine, thioridazine \& mesoridazine) [6]. Tardive Dyskinesia is characterized by a condition of potentially irreversible abnormal involuntary movements of different muscles within the body and can 
occur in the tongue, lips or jaw (e.g., facial grimacing), or consist of purposeless movements of arms, legs, fingers and toes. In some severe cases, TD can include swaying movements of the trunk or hips or affect the muscles associated with breathing and can be quite embarrassing and depending on its severity can be disabling as well. It results in behavioral disturbances, non-adherence, and exacerbation of psychosis [2].

Literatures indicated various prevalence of TD. A meta-analysis study revealed that $6.5 \%$ of patients who were treated with first-generation and predominantly high-potency antipsychotic agents, such as haloperidol or fluphenazine met diagnostic criteria for TD [3]. The cumulative incidence of TD after antipsychotic drug exposure of 1, 5, and 10 years was 5, 27 and 43 percent, respectively [7]. Studies from non-western countries, including Africa are sparse. The study in African Caribbean patients on long-term antipsychotic treatment, showed that in patients with a mean antipsychotic use of approximately 18 years, the yearly incidence rate of TD was $10.2 \%(95 \% \mathrm{Cl}=7.7$ to 13.5$)$ [8]. Several factors in relation with drug treatment have been identified as contributing to the risk of developing TD includes: age, psychiatric diagnosis, gender, organic brain damage, negative symptoms in patients with schizophrenia, antipsychotic dose, duration of treatment, the number of drug free intervals and the history of acute extrapyramidal side effects $[1,9]$.

In spite mental health problem was included in national health policy of Ethiopia, interventions for them are limited. One of the main reasons behind is lack of data on the extent of the problem. Search for literatures revealed, there were very limited published data that investigated the prevalence and associated factors of first-generation antipsychotics induced TD in Ethiopia. So, our study result will add valuable points to or strengthens the knowledge about the prevalence and associated factors of tardive dyskinesia in second world countries including Ethiopia. Therefore, the objective of this study was to determine the prevalence and associated factors of Tardive dyskinesia among psychiatric patients on first-generation antipsychotics at Jimma University specialized hospital (JUSH) psychiatric clinic, Jimma, South west Ethiopia.

\section{Methods}

\section{Study area and period}

The study was conducted from Jun 21 to July 5, 2016 at Jimma University Specialized Hospital (JUSH), Psychiatric clinic to assess the prevalence of TD and associated factors. Jimma University Specialized Hospital is one of the Hospitals in Ethiopia which is found in Jimma city, located $345 \mathrm{~km}$ southwest of Addis Ababa. It is a referral center for the southwestern part of Ethiopia, and currently, the only teaching and referral hospital in the southwestern part of the country. Jimma University Specialized Hospital Psychiatric clinic gives both inpatient and outpatient service for psychiatric patients mostly coming from Jimma area as well as patients referred from other health institutions in the southwestern region of the country. Even if majority of the patients come from Jimma area, the hospital give service for patients come from up to $300 \mathrm{~km}$ radius from Jimma town in the southwest part of Ethiopia. Generally, it gives 
services for more than 30 million populations, which served a huge bulk of the community next to Paulos Hospital in Addis Ababa Ethiopia concerning Psychiatry health facility

\section{Study design}

\section{Source population}

All psychiatric patients on first-generation antipsychotics at Jimma University Specialized Hospital, Psychiatric clinic

\section{Study population}

All Psychiatric patients on first-generation antipsychotics who were attending follow up at Jimma University Specialized Hospital, Psychiatric clinic outpatient department (OPD) during the study period and fulfill the inclusion criteria.

\section{Inclusion Criteria}

All psychiatric patients' age above or equal to18 years and who were on first-generation anti-psychotic drugs treatment at least for 6 months.

\section{Exclusion criteria}

Psychiatric patients whose abnormal involuntary movements were induced by other reasons like infections and seizure were excluded;

\section{Sample size determination and Sampling technique}

Using single population proportion formula and taking the prevalence of antipsychotic induced movement disorders (Tardive Dyskinesia) from the study conducted at Amanuel mental specialized hospital, Addis Ababa, Ethiopia [1] which was 11\%, with $95 \%$ confidence level and marginal error of $5 \%$ the final sample size was 151 individuals. Simple random sampling technique was used to select the study participants. From a total of 912 psychiatric patients who were taking first-generation antipsychotics and on follow-up at Jimma University specialized hospital, psychiatric clinic, we collected their card number from card room and we selected the total study participants (151 individuals) using simple random sampling technique by lottery method.

\section{Study Variables}

\section{Dependent variable:}

The presence of Tardive Dyskinesia (yes/no)

\section{Independent Variables:}


The independent variables included in this study were: Age, Sex, Religion, Ethnicity, Occupational status, Educational status, Current Alcohol use, Current Khat use, Current smoking Cigarette, Current Caffeine use, Diagnosis, Duration of psychiatric disorder, Drug used and Duration of treatment.

\section{Data collection method and tools}

Data were collected by four (4) experienced psychiatric nurses using interviewer administered structured questionnaire and research criteria suggested by Schooler and Kane. The questionnaire used was Abnormal Involuntary Movement Scale (AIMS) which is a rating scale designed in the 1970s to measure involuntary movements known as tardive dyskinesia (TD) [10]. The AIMS test has a total of twelve items rating involuntary movements of various areas of the patient's body. These items are rated on a five-point scale of severity from $0-4$. The scale is rated from 0 (none), 1 (minimal), 2 (mild), 3 (moderate), 4 (severe) and the entire test performed within ten (10) minutes for each patient. For the diagnosis of Tardive dyskinesia (TD), research criteria suggested by Schooler and Kane [11] were used and they are as follows:1. At least 3 months of total exposure to ant-dopaminergic medicinal products, 2. Exclusion of other reasons for involuntary movements, and 3. A minimum global rating of "mild"(i.e. 2 or more on AIMS) was used.

Before data collection time the data collectors were trained by principal investigators on the objectives of the study and how to identify Tardive Dyskinesia in accordance with Abnormal Involuntary Movement Scale (AIMS) for Tardive dyskinesia.

\section{Data Analysis and Processing}

The Data were analyzed using SPSS software program version 20. In order to determine association between TD and independent variables, we employed Logistic regression analysis. Characteristics of study population were described by descriptive statistics. Odds ratio with $95 \%$ confidence interval was calculated to assess the association and statistical significance. Those variables which were found to be significant in the bivariate analysis with a $\mathrm{p}$-value $<0.05$ were retained for further multivariate logistic regression analysis to control for potential confounders and to predict independent factors associated with TD.

\section{Data Quality Assurance}

To maintain the quality of the data, data collectors were trained on how to approach respondents, how to collect and fill all the necessary data and on different variables which are used in the study. Meanwhile, the data collectors were supervised by the principal investigator and One week before the actual survey pretest was carried out among patients with similar socio-demographic characteristic and using similar rating scale which was, Abnormal Involuntary Movement Scale (AIMS) for Tardive dyskinesia. The pretest was conducted at Jimma University Specialized Hospital, psychiatric clinic on $5 \%$ of the total sample size and necessary modification was done before being applied on the study subject. Also, the result of pre- 
test was not included in the final result of the study. Concerning inter rater reliability of data collectors, only 4 experienced psychiatric nurses collected the data under close supervision of the principal investigator.

\section{Operational definitions}

Tardive dyskinesia (TD): In this study TD is defined as patients who scored a minimum global rating of "mild"(i.e. 2 or more on AIMS)[11].

Current alcohol, Khat, cigarettes and caffeine use: Defined as the proportion of individuals who used these substances at least once during the last 1 month preceding the study [12].

\section{Ethical clearance}

Ethical clearance was obtained from the Research Ethical Review Board of Jimma University, institute of health, and the study was performed according to the declaration of Helsinki. The respondents were informed about their right to refuse or agree to participate in the study and written informed consent was obtained from every participant before the start of the data collection.

\section{Results}

\section{Socio-demographic characteristics of respondents}

All 151 participants involved in this study agreed providing response rate of $100 \%, 70.2 \%$ were males and $49 \%$ were found in the age range of less than 30 years. The majority of participants (76.8\%) were Oromo by their ethnicity, $67.5 \%$ were Muslims by their religion, $42.4 \%$ were jobless and the $42.4 \%$ of respondents' educational status were 1-6 grades (Table 1).

Majority of the total participants were found within the age category of $<30$ years (Figure 1 ) and $79.5 \%$ had the diagnosis of schizophrenia and $47 \%$ had gone 5-9 years with their psychiatric illness. The $38.4 \%$ of patients were using chlorpromazine and $49 \%$ of participants took their treatment drugs for more than 5 years and the majority (74.8\%) of the patients reported as they were using caffeine (Table 2).

\section{Prevalence of first-generation antipsychotics induced Tardive Dyskinesia (TD)}

In the current study the prevalence of first-generation antipsychotic induced Tardive dyskinesia among psychiatric patients on first-generation antipsychotics at Jimma University specialized hospital, psychiatric clinic, Ethiopia was $14.6 \%$ (95\% Cl: $10.76 \%, 18.4 \%)$.

\section{Factors associated with first-generation antipsychotic induced Tardive Dyskinesia}

In order to identify the presence of association between first-generation antipsychotic induced Tardive dyskinesia and independent variables we performed bivariate and multivariate logistic regression analyses. In bivariate logistic regression analysis patients' age, religion, chlorpromazine equivalent dose, 
current alcohol use, and current smoking cigarettes were found having significant association with firstgeneration antipsychotic induced tardive dyskinesia and they were candidates for final model of multivariate logistic regression analysis. The final model of multivariate logistic regression analysis showed that age, chlorpromazine equivalent and current smoking cigarettes had statistically significant association with first-generation antipsychotics induced Tardive dyskinesia. The final model of multivariate logistic regression analysis revealed that patients who had smoked cigarettes at least once during the last one month were 1.4 times more likely to develop TD as compared to those who were not smoking cigarettes during the last one month (AOR 1.4, 95\% Cl: 2.6, 7.8) and patients who were in the age category $\geq 45$ year were more than four times more likely to develop TD as compared to those who were found in the age category of $<30$ year (AOR 4.5, 95\% Cl: 9.7, 20.4). Patients who have been on chlorpromazine equivalent dose range $\geq 400 \mathrm{mg}$ /day were 6.5 times more likely to develop TD compared to patients who have been on chlorpromazine equivalent dose range $50-<100 \mathrm{mg} /$ day (AOR $6.5,95 \% \mathrm{Cl}$ :

\section{6 , 26.8) (Table 3).}

\section{Discussion}

This study investigated the prevalence and associated factors of Tardive dyskinesia (TD) among psychiatric patients on first-generation antipsychotics at Jimma University specialized hospital (JUSH) psychiatric clinic, Jimma, South west Ethiopia. The prevalence of TD in the current study was $14.6 \%$ with the range between $10.76 \%$ and $18.4 \%$. Our study result revealed that age, current smoking cigarettes and chlorpromazine equivalent dose range $\geq 400 \mathrm{mg}$ /day had statistically significant association with firstgeneration antipsychotic induced Tardive Dyskinesia (TD).

In this study the prevalence of TD among psychiatric patients on first-generation antipsychotics is closer to the previous finding in Ethiopia which revealed that $11.9 \%$ of patients had TD[1] . On the other hand, the prevalence is greater than that found in Arab among psychotic patients treated with first-generation antipsychotic which shows the prevalence was 5.9\% [9]. The present study result is also lower than the findings of studies done in Turkey and Indian $[13,14]$ in which the prevalence of first-generation antipsychotics induced TD was $22.5 \%$ and $26.4 \%$ respectively. This variation could be due to different possible reasons like characteristics of the participants. In the current study we included patients with different diagnosis including schizophrenia, bipolar disorder and MDD with psychotic feature those were getting first-generation antipsychotic drugs. But studies like in Turkey and Indian did on only schizophrenic patients. The other point is also in the current study we include patients who took medications at least for six (6) months and above. But some the compared studies like study in Indian included participants who took medications for at least one (1) year and above.

Our study revealed that patients who had smoked cigarettes at least once during the last one month were 1.4 times more likely to develop TD as compared to patients who were not smoking cigarettes during the last one month (AOR 1.4,95\% Cl: 2.6,7.8) and this was similar with the result of previous studies which showed the prevalence of TD was significantly higher among smokers than non-smokers [15]. Out of the first-generation antipsychotics included in this study, Haloperidol, chlorpromazine, and thioridazine are 
metabolized by CYP enzymes except trifluoperazine which is metabolized by UDPglucuronosyltransferase1A4. Even so, Smoking is associated with induction of CYP1A2, the study in Chinese revealed that there is no association between the $C \rightarrow A$ genetic polymorphism of CYP1A2 and TD [15]. Contrary to our study result, a study conducted in the eastern cape of south Africa showed that a history of smoking was not associated with an increased or decreased risk, although fewer subjects with TD were smokers and they had smoked for fewer years [16]

In our study patients who were in the age category $\geq 45$ year were more than four times more likely to develop TD as compared to patients who were found in the age category of $18-30$ year (AOR $4.5,95 \% \mathrm{Cl}$ : $9.7,20.4)$ and it is in line with the results of many previous studies which revealed that the prevalence of TD is high among older patients $[1,9,17-19]$. This result indicates that whenever the professionals prescribe first-generation antipsychotics, they have to consider the patients' age and appropriately prescribe the medications as described in prescription guidelines. For instance, our study result showed that one of the associated factors for TD is getting relatively high dose of medications especially chlorpromazine. Therefore, the professionals could consider the patients' age and adjust the dose in order to prevent the TD.

The current study result shows that patients who had been getting chlorpromazine equivalent dose range $\geq 400 \mathrm{mg} /$ day were 6.5 times more likely to develop TD as compared to patients who had been getting chlorpromazine equivalent dose range $50-<100 \mathrm{mg} /$ day (AOR 6.5, 95\% Cl: 2.6, 26.8) and this result was consistent with some previous study results $[1,16,20]$. This result forwards the message that the treating professionals (clinicians) have to put the patients on the effective lowest dose as much as possible. From our clinical experience, some times the treating clinicians will put the patients on unnecessary high dose which could expose the patients to different side effects including antipsychotics induced movement disorders.

The study has some limitations including: it was cross-sectional study and cannot show the cause-effect relationship between Tardive Dyskinesia and independent variables and also the independent factors included in this study were not comprehensive enough. Questions about some variables like current substance use (alcohol, Khat and cigarettes) are sensitive issue and social desirability bias is possible.

\section{Conclusions}

Considerable number of psychiatric patients were suffered from first-generation antipsychotics induced TD. Age, current smoking cigarettes and chlorpromazine equivalent dose were found to be significantly associated with first-generation antipsychotics induced TD. The study finding will provides information to form rational foundation for prevention and planning to bring change in contributing factors for developing TD. Also, the result could serve as base line information for further study. The study recommended that stakeholders should consider and appropriately address these statistically identified associated factors in order to reduce/prevent antipsychotics induced TD. Also, it is beneficial if 
professional care givers give attention for patients who are sensitive to antipsychotics like old age patients during treating them.

\section{Abbreviations}

AIMS- Abnormal Involuntary Movement Scale

AOR- Adjusted Odds Ratio

COR- Crude Odds Ratio

JUSH- Jimma University Specialized Hospital

OPD- Outpatient Department

TD- Tardive Dyskinesia

\section{Declarations}

\section{Ethics approval and consent to participate}

The study was approved by the ethical review board of the College of Health Sciences, Jimma University. The respondents were informed about their right to refuse or agree to participate in the study and an oral informed consent was obtained from every participant before the start of the data collection. We did not include patients' personal information like their name in the study.

\section{Consent for publication}

Not applicable

\section{Availability of data and material}

The datasets analyzed during this study is available from the corresponding author on reasonable request.

\section{Competing interests}

The authors declare that they have no competing interests.

\section{Funding}

Not applicable.

\section{Authors' contributions}


TA contributed to the designing research, conduct and analysis of the research, drafting the manuscript, critically reviewed and approved the manuscript for publication.

All authors read and approved the final manuscript.

DT contributed to the design, conduct and analysis of the research and in the review of the manuscript.

WT contributed to the designing research, conduct and analysis and in the review of the manuscript

\section{Acknowledgements}

Not applicable.

\section{References}

1. Taye, H., T. Awoke, and J. Ebrahim, Antipsychotic medication induced movement disorders: The case of Amanuel Specialized Mental Hospital, Addis Ababa, Ethiopia.

2. Albayrak, Y. and O. Ekinci, Duloxetine-associated tardive dyskinesia resolved with fluvoxamine: a case report. Journal of clinical psychopharmacology, 2012. 32(5): p. 723-724.

3. Carbon, M., et al., Tardive dyskinesia risk with first-and second-generation antipsychotics in comparative randomized controlled trials: a meta-analysis. World Psychiatry, 2018. 17(3): p. 330340 .

4. Margolese, H.C., et al., Tardive dyskinesia in the era of typical and atypical antipsychotics. Part 2: Incidence and management strategies in patients with schizophrenia. The Canadian Journal of Psychiatry, 2005. 50(11): p. 703-714.

5. Cornett, E.M., et al., Medication-induced tardive dyskinesia: a review and update. Ochsner Journal, 2017. 17(2): p. 162-174.

6. Lieberman, J.A., et al., Atypical and conventional antipsychotic drugs in treatment-naive first-episode schizophrenia: a 52-week randomized trial of clozapine vs chlorpromazine. Neuropsychopharmacology, 2003. 28(5): p. 995.

7. Tarsy, D. and R.J. Baldessarini, Epidemiology of tardive dyskinesia: is risk declining with modern antipsychotics? Movement disorders: official journal of the Movement Disorder Society, 2006. 21(5): p. 589-598.

8. van Harten, P.N., et al., Incidence of tardive dyskinesia and tardive dystonia in African Caribbean patients on long-term antipsychotic treatment: the Curaçao extrapyramidal syndromes study $V$. The Journal of clinical psychiatry, 2006. 67(12): p. 1920.

9. Osman, A., et al., Neuroleptic-induced tardive dyskinesia among Arab psychotic patients/La dyskinesie tardive post-neuroleptique chez des patients arabes psychotiques. Eastern Mediterranean Health Journal, 2007. 13(3): p. 625-633. 
10. Lane, R.D., et al., Assessment of tardive dyskinesia using the Abnormal Involuntary Movement Scale. Journal of Nervous and Mental Disease, 1985.

11. Schooler, N.R. and J.M. Kane, Research diagnoses for tardive dyskinesia. Archives of General Psychiatry, 1982. 39(4): p. 486-487.

12. Abdeta, T., et al., Prevalence, withdrawal symptoms and associated factors of khat chewing among students at Jimma University in Ethiopia. BMC psychiatry, 2017. 17(1): p. 142.

13. Nalbant, A., et al., Tardive Dyskinesia in Long Term Hospitalized Patients with Schizophrenia/Uzun süreli ve yatirilarak izlenen sizofreni hastalarinda tardiv diskinezi. Dusunen Adam, 2016. 29(3): p. 259.

14. Achalia, R.M., et al., Prevalence and risk factors associated with tardive dyskinesia among Indian patients with schizophrenia. Asian journal of psychiatry, 2014. 9: p. 31-35.

15. Chong, S.-A., E.-C. Tan, and C.H. Tan, Smoking and tardive dyskinesia: lack of involvement of the CYP1A2 gene. Journal of Psychiatry and Neuroscience, 2003. 28(3): p. 185.

16. Patterson, B.D., D. Swingler, and S. Willows, Prevalence of and risk factors for tardive dyskinesia in a Xhosa population in the Eastern Cape of South Africa. Schizophrenia research, 2005. 76(1): p. 89-97.

17. Kane, J.M., M. Woerner, and J. Lieberman, Tardive dyskinesia: prevalence, incidence, and risk factors. Journal of clinical psychopharmacology, 1988. 8(4 Suppl): p. 52S-56S.

18. Sadock, B.J. and V.A. Sadock, Kaplan and Sadock's synopsis of psychiatry: Behavioral sciences/clinical psychiatry. 2011: Lippincott Williams \& Wilkins.

19. Jeste, D.V., Tardive dyskinesia in older patients. Journal of Clinical Psychiatry, 2000. 61: p. 27-32.

20. Jeste, D.V., et al., Incidence of tardive dyskinesia in early stages of low-dose treatment with typical neuroleptics in older patients. American Journal of Psychiatry, 1999. 156(2): p. 309-311.

\section{Tables}

Table 1: Socio-demographic characteristics of psychiatric patients on first-generation antipsychotics at JUSH, psychiatric clinic, Jimma, Ethiopia, 2016.

\begin{tabular}{|lllcc|}
\hline Socio-demographic characteristics & & Count (N) & Percentage (\%) \\
\hline Educational & status & Can't read and write & 20 & $13.2 \%$ \\
\cline { 2 - 4 } & $1-6$ grades & 64 & $42.4 \%$ \\
\cline { 2 - 4 } & $7-12$ grades & 43 & $28.5 \%$ \\
\hline Ethnicity & $>12$ grades & 24 & $15.9 \%$ \\
& Oromo & 116 & $76.8 \%$ \\
\cline { 2 - 4 } & Amhara & 17 & $11.3 \%$ \\
\cline { 2 - 4 } & Kaffa & 10 & $6.6 \%$ \\
\cline { 2 - 4 } & Others & 8 & $5.3 \%$ \\
\hline Religion & Orthodox & 33 & $21.9 \%$ \\
\cline { 2 - 4 } & Muslim & 102 & $67.5 \%$ \\
\cline { 2 - 4 } & Protestant & 16 & $10.6 \%$ \\
\hline Occupation & Has job & 87 & $57.6 \%$ \\
\hline
\end{tabular}

Page $11 / 16$ 
Table 2: Clinical and current substance use characteristics of psychiatric patients on first-generation antipsychotics at JUSH, psychiatric clinic, Jimma, Ethiopia, 2016.

\begin{tabular}{|c|c|c|c|}
\hline \multicolumn{2}{|l|}{ Clinical characteristics } & Count $(\mathrm{N})$ & Percentage (\%) \\
\hline \multirow[t]{2}{*}{ Diagnosis of patient } & Schizophrenia & 120 & $79.5 \%$ \\
\hline & Others* & 31 & $20.5 \%$ \\
\hline \multirow[t]{3}{*}{ Duration of psychiatric disorder } & $<5$ year & 61 & $40.4 \%$ \\
\hline & 5-9 year & 71 & $47.0 \%$ \\
\hline & $>=10$ year & 19 & $12.6 \%$ \\
\hline \multirow[t]{3}{*}{ Types of Drugs used } & Haloperidol & 48 & $31.8 \%$ \\
\hline & Chlorpromazine & 58 & $38.4 \%$ \\
\hline & Thioridazine and Trifluoperazine & 45 & $29.8 \%$ \\
\hline \multirow[t]{3}{*}{ Duration of treatment } & 3 month $-<6$ months & 6 & $4.0 \%$ \\
\hline & 6 month - 5 year & 71 & $47.0 \%$ \\
\hline & $>=5$ year & 74 & $49.0 \%$ \\
\hline \multirow[t]{3}{*}{ Chlorpromazine equivalent dose (mg/day) } & $50-<100$ & 13 & 8.6 \\
\hline & $100-<400$ & 112 & 74.2 \\
\hline & $>=400$ & 26 & 17.2 \\
\hline Current Alcohol use & Yes & 6 & $4.0 \%$ \\
\hline Current Caffeine use & Yes & 113 & $74.8 \%$ \\
\hline Current Smoking cigarette & Yes & 12 & $7.9 \%$ \\
\hline Current Khat use & Yes & 70 & $46.4 \%$ \\
\hline
\end{tabular}

Others* (Bipolar disorder and Major Depressive Disorder with psychotic features)

Table 3: Factors associated with antipsychotic induced TD among psychiatric patients on first-generation antipsychotics at JUSH, psychiatric clinic, Jimma, Ethiopia, 2016. 


\begin{tabular}{|l|l|l|l|l|l|l|}
\hline Variables & \multicolumn{2}{|l|}{$\begin{array}{l}\text { Antipsychotic induced } \\
\text { TD }\end{array}$} & p-value & $\begin{array}{l}\text { COR } \\
(95 \% \mathrm{CI})\end{array}$ & $\begin{array}{l}\text { p-value } \\
(95 \% \mathrm{CI})\end{array}$ \\
\cline { 2 - 6 } & Yes & No & & & \\
& & & &
\end{tabular}

\section{Age}

\begin{tabular}{|l|l|l|l|l|l|l|}
\hline $18-30$ & 7 & 68 & Reference & Reference & Reference & Reference \\
\hline $30-44$ & 11 & 48 & 0.15 & $2.4(0.7-7.8)$ & 0.2 & $\begin{array}{l}2.6(0.6- \\
11.3)\end{array}$ \\
\hline$\geq 45$ & 6 & 11 & $0.01^{*}$ & $5.3(1.5-18.7)$ & $0.04^{*}$ & $\begin{array}{l}4.5(9.7- \\
20.4)\end{array}$ \\
\hline
\end{tabular}

\section{Sex}

\begin{tabular}{|l|c|c|l|l|l|l|}
\hline Male & 15 & 91 & Reference & Reference & Reference & Reference \\
\hline Female & 9 & 36 & 0.37 & $\begin{array}{l}0.66(0.26- \\
1.6)\end{array}$ & & \\
\hline
\end{tabular}

\section{Educational status}

\begin{tabular}{|l|c|l|l|l|l|l|}
\hline Can't read and write & 4 & 16 & 0.27 & $0.36(0.1-2.2)$ & & \\
\hline $1-6$ grades & 8 & 56 & 0.58 & $\begin{array}{l}0.64(0.12- \\
3.2)\end{array}$ & \\
\hline $7-12$ grades & 10 & 33 & 0.14 & $0.3(0.1-1.5)$ & & \\
\hline$>12$ grades & 2 & 22 & Reference & Reference & Reference & Reference \\
\hline
\end{tabular}

\section{Occupation}

\begin{tabular}{|l|c|c|l|l|l|l|}
\hline Has job & 12 & 75 & Reference & Reference & Reference & Reference \\
\hline No job & 12 & 52 & 0.41 & $\begin{array}{l}0.69(0.29- \\
1.7)\end{array}$ & & \\
\hline
\end{tabular}

\section{Ethnicity}

\begin{tabular}{|l|c|c|l|l|l|l|}
\hline Oromo & 15 & 101 & Reference & Reference & Reference & Reference \\
\hline Amhara & 4 & 13 & 0.25 & $\begin{array}{l}0.48(0.14- \\
1.7)\end{array}$ & \\
\hline Kaffa & 3 & 7 & 0.15 & $0.35(0.1-1.5)$ & & \\
\hline Others & 2 & $6 \quad 0.35$ & $0.45(0.1-2.4)$ & \\
\hline
\end{tabular}




\section{Religion}

\begin{tabular}{|l|c|c|l|l|l|l|}
\hline Orthodox & 10 & 23 & $0.02^{*}$ & $3.3(1.3-8.5)$ & 0.06 & $\begin{array}{l}3.6(0.95- \\
14.0)\end{array}$ \\
\hline Muslim & 12 & 90 & Reference & Reference & Reference & Reference \\
\hline Protestant & 2 & 14 & 0.19 & $3.0(0.6-15.9)$ & 0.13 & $\begin{array}{l}5.1(0.62- \\
42.3)\end{array}$ \\
\hline
\end{tabular}

\section{Diagnosis of patient}

\begin{tabular}{|l|c|c|l|l|l|l|}
\hline Schizophrenia & 17 & 103 & Reference & Reference & Reference & Reference \\
\hline Others & 7 & 24 & 0.26 & $\begin{array}{l}0.57(0.21- \\
1.5)\end{array}$ & & \\
\hline
\end{tabular}

\section{Duration of psychiatric disorder}

\begin{tabular}{|l|c|c|l|l|l|l|}
\hline$<5$ year & 9 & 52 & Reference & Reference & Reference & Reference \\
\hline 5-9 year & 11 & 60 & 0.91 & $\begin{array}{l}0.94(0.36- \\
2.5)\end{array}$ & & \\
\hline$>=10$ year & 4 & 15 & 0.52 & $\begin{array}{l}0.65(0.17- \\
2.4)\end{array}$ & & \\
\hline
\end{tabular}

\section{Drug used}

\begin{tabular}{|l|c|c|l|l|l|l|}
\hline Haloperidol & 10 & 38 & 0.51 & $0.7(0.24-2.0)$ & & \\
\hline Chlorpromazine & 7 & 51 & 0.61 & $\begin{array}{l}1.3(0.43- \\
4.15)\end{array}$ & & \\
\hline $\begin{array}{l}\text { Thioridazine and } \\
\text { Trifluoperazine }\end{array}$ & 7 & 38 & Reference & Reference & Reference & Reference \\
\hline
\end{tabular}

\section{Duration of treatment}

\begin{tabular}{|l|c|c|l|l|l|l|}
\hline 3months -<6 months & 1 & 5 & Reference & Reference & Reference & Reference \\
\hline 6 month -5year & 9 & 62 & 0.78 & $\begin{array}{l}1.4(0.1- \\
13.12)\end{array}$ & & \\
\hline$>=5$ year & 14 & 60 & 0.89 & $\begin{array}{l}0.8(0.09- \\
7.9)\end{array}$ & \\
\hline
\end{tabular}

Chlorpromazine equivalent dose (mg/day) 


\begin{tabular}{|l|l|l|l|l|l|l|} 
& & & & \\
\hline $100-<400$ & 8 & 104 & $0.03^{*}$ & $\begin{array}{l}6.4(11.8- \\
34.8)\end{array}$ & 0.06 & $\begin{array}{l}4.3(0.92- \\
16.9\end{array}$ \\
\hline$>=400$ & 14 & 12 & $0.001^{*}$ & $\begin{array}{l}10.2(5.3- \\
43.5)\end{array}$ & $0.001^{*}$ & $\begin{array}{l}6.5(2.6- \\
26.8)\end{array}$ \\
\hline
\end{tabular}

\section{Current Alcohol use}

\begin{tabular}{|l|l|l|l|l|l|l|}
\hline Yes & 4 & 4 & $0.02^{*}$ & $6.2(1.4-26.6)$ & 0.95 & $\begin{array}{l}1.1(0.13- \\
8.6)\end{array}$ \\
\hline No & 20 & 123 & Reference & Reference & Reference & Reference \\
\hline
\end{tabular}

\section{Current Caffeine use}

\begin{tabular}{|l|c|c|l|l|l|l|}
\hline Yes & 19 & 94 & 0.59 & $0.8(0.26-2.2)$ & & \\
\hline No & 5 & 33 & Reference & Reference & Reference & Reference \\
\hline
\end{tabular}

\section{Current Smoking cigarette}

\begin{tabular}{|l|c|c|l|l|l|l|}
\hline Yes & 5 & 7 & $0.02^{*}$ & $4.5(1.3-15.7)$ & $0.04^{*}$ & $\begin{array}{l}1.4(2.6- \\
7.8)\end{array}$ \\
\hline No & 19 & 120 & Reference & Reference & Reference & Reference \\
\hline
\end{tabular}

\section{Current Khat use}

\begin{tabular}{|l|l|l|l|l|l|l|}
\hline Yes & 13 & 57 & 0.4 & $0.69(0.29-$ & & \\
\hline No & 11 & 70 & Reference & Reference & Reference & Reference \\
\hline
\end{tabular}

*statistically significant

\section{Figures}




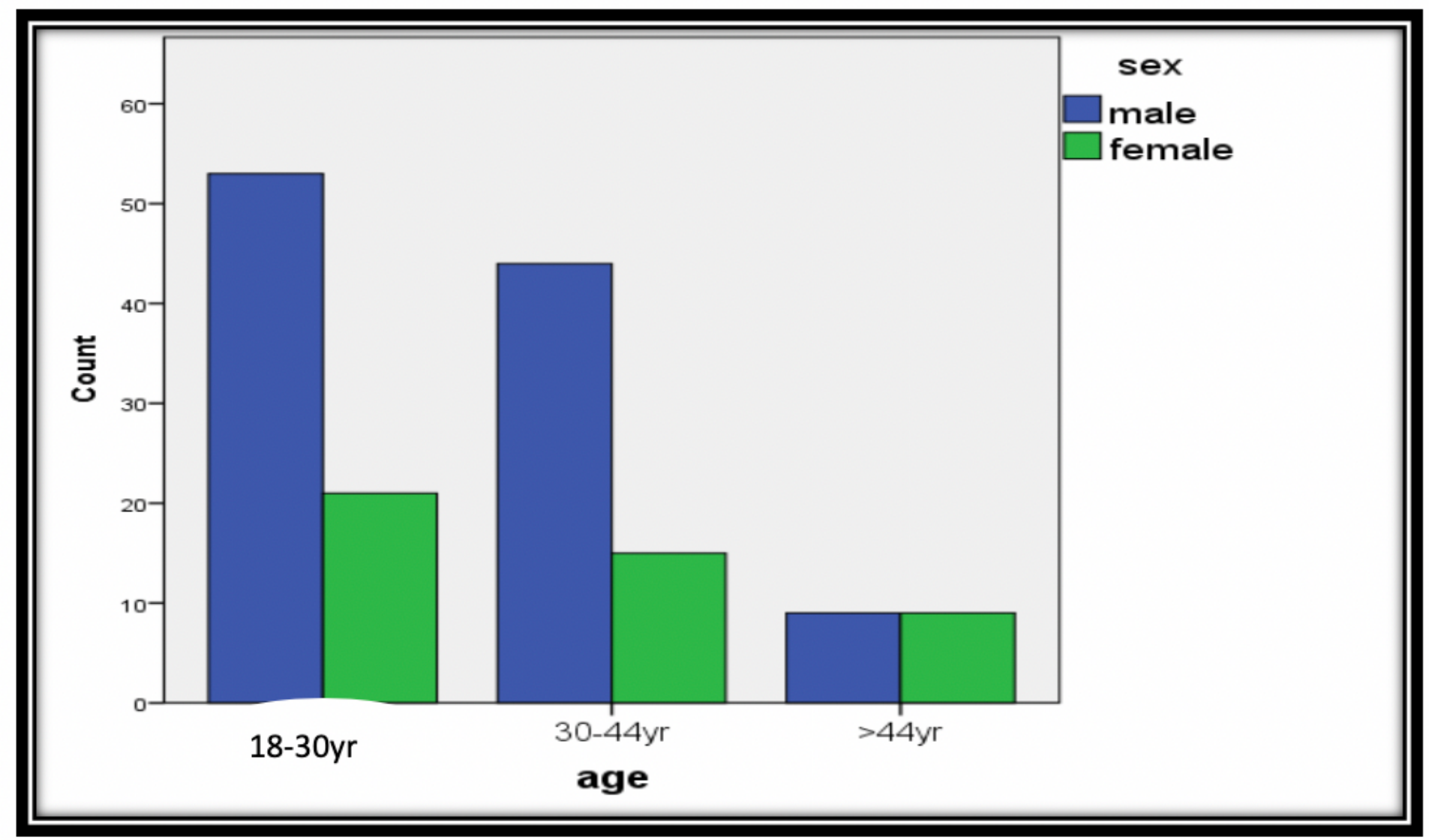

Figure 1

Age and sex of psychiatric patients who were on first-generation antipsychotics at JUSH psychiatric clinic, 2016 